\title{
CONTAMINAÇÃO DE AQÜÍFERO POR HIDROCARBONETOS: ESTUDO DE CASO NA VILA TUPI, PORTO VELHO - RONDÔNIA
}

\author{
Elcimar Juarez Forte* \\ Laboratório Central de Polícia Técnica, Polícia Civil de Rondônia, Rua José Adelino da Silva, 4111, 78930-830 Porto Velho - \\ RO, Brasil \\ Mariangela Soares Azevedo, Ronaldo Cavalcante de Oliveira e Ronaldo de Almeida \\ Departamento de Química, Universidade Federal de Rondônia, Rodovia BR 364, km 9,5, 78900-500 Porto Velho - RO, Brasil
}

Recebido em 2/6/06; aceito em 9/3/07; publicado na web em 30/7/07

\begin{abstract}
HYDROCARBON CONTAMINATION IN GROUNDWATER: THE CASE OF TUPI VILLAGE, PORTO VELHO-RO. Underground storage tanks (UST) are widely used in the Porto Velho area. A large number of these USTs are in bad condition due to corrosion processes causing groundwater contamination. A large number of these leaking underground fuel tanks (LUFT) are in urban areas but due to the lack of water quality monitoring, they are only detected when there is a high contamination level. This study identified petroleum hydrocarbons, derived from a LUFT, by a silica gel/petroleum ether partitioning gravimetric method and by gas chromatographic analysis of samples collected in wells dug in a gas station and in houses in the aforementioned neighborhood.
\end{abstract}

Keywords: contamination; fuels; hydrocarbons.

\section{INTRODUÇÃO}

No Brasil as preocupações relacionadas ao potencial de contaminação de águas subterrâneas por derramamentos de combustíveis vêm crescendo em diversas cidades, fazendo com que muitas elaborem legislação sobre o tema, como é o caso de São Paulo, Belo Horizonte, Florianópolis e Curitiba.

No estado de São Paulo, no período de 1984 a 2001, foram realizados 438 atendimentos emergenciais envolvendo vazamento de combustíveis em postos de revenda e de prestação de serviços. Cerca de $10 \%$ de todas as emergências atendidas no estado, conforme a Divisão de Tecnologia de Riscos Ambientais da CETESB são provenientes de vazamentos em postos e sistemas retalhistas de combustíveis ${ }^{1}$.

Conforme dados da Agência Nacional de Petróleo - $\mathrm{ANP}^{2}$, no final de 2001 tinham cadastro no Brasil 32.697 postos, registro este $12,3 \%$ superior ao ano anterior. A cidade de Porto Velho dispõe de aproximadamente 97 postos revendedores de combustíveis, de acordo com dados da $\mathrm{ANP}^{2}$ e Secretaria de Estado de Desenvolvimento Ambiental de Rondônia - SEDAM, tendo, portanto, um número aproximado de 400 tanques de armazenamento de combustíveis, sem contar com as 14 empresas que atuam como Bases de Distribuição de Combustíveis Líquidos Derivados de Petróleo e de Álcool. Não se sabem as condições da maioria desses tanques, que têm uma vida útil de 15 anos aproximadamente.

Com 334.661 habitantes, conforme censo demográfico de 2000 do IBGE, Porto Velho tem 2,4\% de domicílios abastecidos com água potável, cuja captação é feita principalmente de mananciais de superfície ${ }^{3}$. Poços tubulares e escavados do tipo "Amazonas" são as fontes de água do restante, nem sempre construídos obedecendo a critérios técnicos, tornando a população usuária deste tipo de abastecimento vulnerável aos riscos de consumir água contaminada por combustíveis provenientes de vazamentos de tanques de armazenamento subterrâneos dos postos revendedores e distribuidoras, além de outros contaminantes. Esses vazamentos podem acar-

*e-mail: galego.ro@uol.com.br retar sérios impactos ambientais devido à contaminação do solo e das águas subterrâneas, comprometendo a qualidade dos recursos hídricos e seu uso para abastecimento.

Este trabalho se fixou na Vila Tupi aproveitando-se requisição da SEDAM ao Instituto de Criminalística e ao Laboratório Central de Polícia Técnica da Polícia Civil do Estado de Rondônia para que participassem de estudos visando identificar possíveis contaminações na água de poços de residências da Vila Tupi, localizadas próximas a um posto revendedor de combustíveis situado na Rua Campos Sales com BR-364, na cidade de Porto Velho e em outras áreas da cidade.

Quando ocorre um vazamento de combustível a partir de tanques de armazenamento subterrâneos, forças gravitacionais atuam direcionando o fluxo para as porções mais profundas do solo (Figura 1). Os hidrocarbonetos de petróleo penetram no subsolo como líquido de forma não aquosa - "NAPL (Non-Aqueous Phase Liquids)". Conforme sua densidade, os NAPLs são divididos em líquidos leves na fase não aquosa - "LNAPL (Light Non-Aqueous Phase Liquids)" - que são compostos com densidade menor que a água (como exemplo os hidrocarbonetos do petróleo: benzeno, tolueno, etilbenzeno, xilenos) e líquidos densos na fase não aquosa - "DNAPL (Dense Non-Aqueous Phase Liquids)" - compostos com densidades maiores que a da água ${ }^{4}$.

Os principais contaminantes capazes de impactar o meio ambiente em casos de derramamentos de combustíveis são os hidrocarbonetos mono aromáticos ${ }^{5}$ (benzeno, tolueno, etilbenzeno e xilenos - os BTEX) e os policíclicos aromáticos, como naftaleno e benzopireno ${ }^{6}$. O benzeno é sabidamente carcinogênico, sendo os outros, tolueno, etilbenzeno e os xilenos, considerados tóxicos ${ }^{7,8}$.

A gasolina é composta por hidrocarbonetos e aditivos usados para melhorar o desempenho do combustível e do motor e apresenta boa mobilidade, atingindo a água subterrânea por infiltração quando de um derramamento 9 . O diesel é composto por hidrocarbonetos contendo 10 a 12 carbonos e, devido ao maior peso molecular, seus componentes são menos voláteis, menos solúveis em água e apresentam menor mobilidade no ambiente que os componentes da gasolina. As proporções de BTEX presentes no diesel são geralmente baixas ${ }^{10}$. 
Normalmente, um vazamento de combustível em um tanque de abastecimento promove diferentes fases de contaminação: livre (ou móvel), adsorvida, dissolvida, vaporizada e condensada ${ }^{11,12}$.

Os principais fenômenos físicos que controlam a migração de compostos orgânicos no solo são: advecção - que é o mecanismo no qual os contaminantes seguem coincidentemente o fluxo subterrâneo; dispersão - mecanismo responsável pela diminuição de concentração dos contaminantes e, atenuação - que é a redução de contaminantes transportados pela advecção. A advecção e a dispersão irão transportar e espalhar, respectivamente, a pluma no meio poroso $^{13,14}$.

Nas contaminações com a gasolina brasileira, o etanol adicionado ${ }^{15}$ adquire grande importância, pois sua presença altera o comportamento da gasolina em termos de solubilidade, mobilidade e degradação ${ }^{16}$. Ao entrar em contato com a água, o etanol passa para a fase aquosa, aumentando a solubilidade dos compostos mono aromáticos BTEX. A degradação natural (biodegradação) do etanol será preferencial sobre os constituintes solúveis da gasolina ${ }^{17}$, aumentando a persistência destes compostos na água subterrânea ${ }^{18}$.

O alcance da pluma de contaminação sob a zona de gasolina na fase livre pode chegar a distâncias consideráveis. Plumas contendo misturas de gasolina e álcool irão contaminar áreas maiores que plumas sem a presença de etanol ${ }^{19}$. $\mathrm{O}$ avanço das manchas poluidoras pode ser acelerado pela exploração do aquíffero, na medida em que aumenta a velocidade do fluxo subterrâneo em direção às áreas onde está havendo a retirada de água ${ }^{20}$.

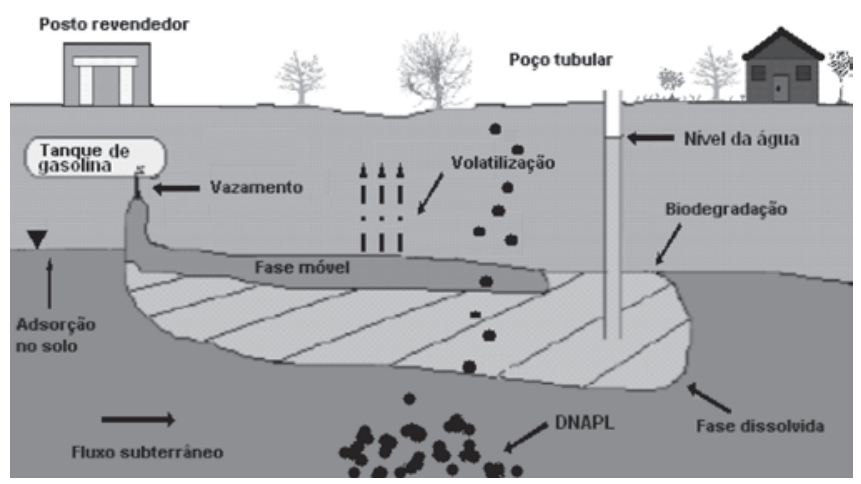

Figura 1. Contaminação de solo e água subterrânea. Adaptada da ref. 5

Este trabalho teve como objetivo verificar a presença de hidrocarbonetos para caracterizar a contaminação e a migração da pluma, utilizando a partição gravimétrica, técnica acessível para a realidade de Rondônia, não se atendo à avaliação da periculosidade.

\section{PARTE EXPERIMENTAL}

\section{Área de estudo}

A Vila Tupi está localizada na zona sul da cidade de Porto Velho, no entroncamento da BR-364 sentido Acre e Rua Campos Sales (Latitude 20L 401286.877, Longitude 9029021.633, coordenadas do Poço de Monitoramento 04), sendo área residencial, contando com comércios e com cerca de 100 famílias residindo no local. Distando aproximadamente $50 \mathrm{~m}$ da Vila, na confluência da BR-364 com Rua Campos Sales, no lado oposto (Latitude 20L 401326.517, Longitude 9028977.242 - coordenadas do Poço de Monitoramento no 02), em nível mais elevado que a Vila situa-se um posto revendedor de combustíveis, potencial fonte poluidora do lençol freático por combustível.

Durante fevereiro de 2004, foram realizadas 10 perfurações de sondagem (Poços de Monitoramento) no pátio do posto se direcionando até a Vila Tupi, sendo 6 utilizadas neste trabalho ${ }^{21}$. Foram identificados sedimentos argilosos, areno-argilosos, arenosos e seixos inconsolidados, além de concreções lateríticas caracterizando coberturas aluvionares encaixadas em um vale. Verificouse a presença de aterro na área em que se localizam os poços PM01 e PM-02, visto que o terreno do posto é originariamente em desnível, com parte de suas instalações edificada em área aterrada.

O fluxo subterrâneo, um parâmetro importante na avaliação de risco de contaminação das águas subterrâneas e que é indispensável no estudo da evolução de plumas de contaminação, dá-se de SE para NW, ou seja, da BR-364 em direção a Vila Tupi, com o posto topograficamente intermediário ${ }^{21}$.

\section{Materiais e métodos}

Na área estudada, do Posto até a Vila Tupi, foram utilizados como pontos de coleta de amostras os poços de monitoramento perfurados por Melo Jr. e Costi ${ }^{21}$, com n amostral igual a 6, além de 4 amostras coletadas de poços de residências da Vila.

Para coleta foram utilizados frascos de vidro de boca larga, cor âmbar, com capacidade para 1,0 L, usados comumente para acondicionar reagentes químicos, previamente descontaminados no Laboratório de Biogeoquímica Ambiental da Universidade Federal de Rondônia UNIR, segundo metodologia CETESB ${ }^{22}$. Também foram usados um amostrador para água fabricado em PVC e válvula de retenção; medidor eletrônico de nível da água; kit (modelo Meter-handylab Schott ${ }^{\circledR}$ ) para determinação in loco dos parâmetros físico-químicos da água ( $\mathrm{pH}$, condutividade elétrica, temperatura do ar e temperatura da água); receptor de GPS (modelo GPS III Plus Garmin's ${ }^{\circledR}$ ) para obtenção das coordenadas geográficas (em UTM - "Universal Transversal Mercator" - ver os mapas de isoconcentrações) dos poços amostrados.

O índice de hidrocarbonetos - "TPH (Total Petroleum Hydrocarbon)" - foi determinado com cromatógrafo a gás (Siemens Sichchromat) equipado com detector de ionização de chama (DIC), coluna CP SIL 8CB $10 \mathrm{~m} \mathrm{X} \mathrm{0,25} \mathrm{mm,} \mathrm{autosampler} \mathrm{Varian} \mathrm{(Método}$ DIN ISO 9377-2, com Limite de Detecção de $0,1 \mathrm{mg} \mathrm{L}^{-1}$ ). A principal limitação deste parâmetro consiste no fato de que os hidrocarbonetos totais de petróleo (TPH) são indicadores da presença ou não de hidrocarbonetos no meio, não determinando, entretanto, o tipo de substância presente, impossibilitando a avaliação do grau de periculosidade individual.

$\mathrm{O}$ teor de $\mathrm{BTEX}^{23}$ foi analisado com o equipamento Thermoquest GCQ ("high resolution gás chromatograph"), sistema íon trap, autosampler CTC, headspace sampler Varian, detector MSD, coluna CP SIL 8CB MS $30 \mathrm{~m} \mathrm{X} \mathrm{0,25} \mathrm{mm.} \mathrm{Tanto} \mathrm{o} \mathrm{teor} \mathrm{de} \mathrm{BTEX} \mathrm{quanto}$ TPH foram determinados pelo Laboratório Innolab do Rio de Janeiro, que utilizou ainda padrões de hidrocarbonetos C-10 até C-38 e os padrões deuterados Perdeuterobenzene, Toluene-d8, D-ortoXileno nas análises de BTEX.

As análises de óleos e graxas, uma adaptação de Macedo $^{24}$ do "Standard Methods", e hidrocarbonetos por partição gravimétrica, também uma adaptação do Standard Methods ${ }^{25}$ foram efetuadas no Laboratório de Biogeoquímica Ambiental da UNIR, sendo usados os seguintes reagentes, todos em grau P.A.: ácido clorídrico 1:1 (v/ v) da Merck, éter de petróleo (Vetec), sulfato de sódio anidro (Vetec) e sílica gel para cromatografia em coluna (Vetec). Como vidraria foram usados erlenmeyer de $500 \mathrm{~mL}$, funil de separação de $2,0 \mathrm{~L}$ com rolha e torneira de teflon, balão de destilação de $125 \mathrm{~mL}$, além de bomba de vácuo, banho-maria e papel de filtro, sendo realizados branco do equipamento (amostrador) e branco com água destilada.

O perfil cromatográfico foi realizado no Centro de Perícias Científicas Renato Chaves, Gerência de Castanhal, no estado do Pará, utilizando um cromatógrafo a gás GC-3300, da Varian com detector 
de ionização de chama, injetor split-less, colunas porapak $30 \mathrm{~m}$ e $\mathrm{OV}-17$, sendo usado o head space (aquecimento da amostra em frasco tipo penicilina lacrado em estufa de esterilização a $150{ }^{\circ} \mathrm{C}$ ); nitrogênio como gás de arraste.

No Laboratório de Biogeoquímica Ambiental da UNIR, com o software Surfer 8.0 da Golden Software, Inc. ${ }^{26}$, utilizado em análises hidrogeológicas, foram confeccionados, utilizando-se o método de krigagem $^{27}$, mapas de sentido do fluxo subterrâneo, cotas de nível e nível de água. Os mapas de isoconcentrações de óleos e graxas e hidrocarbonetos foram confeccionados utilizando-se o método de interpolação a partir do algoritmo inverso da distância ao quadrado.

\section{Amostragem}

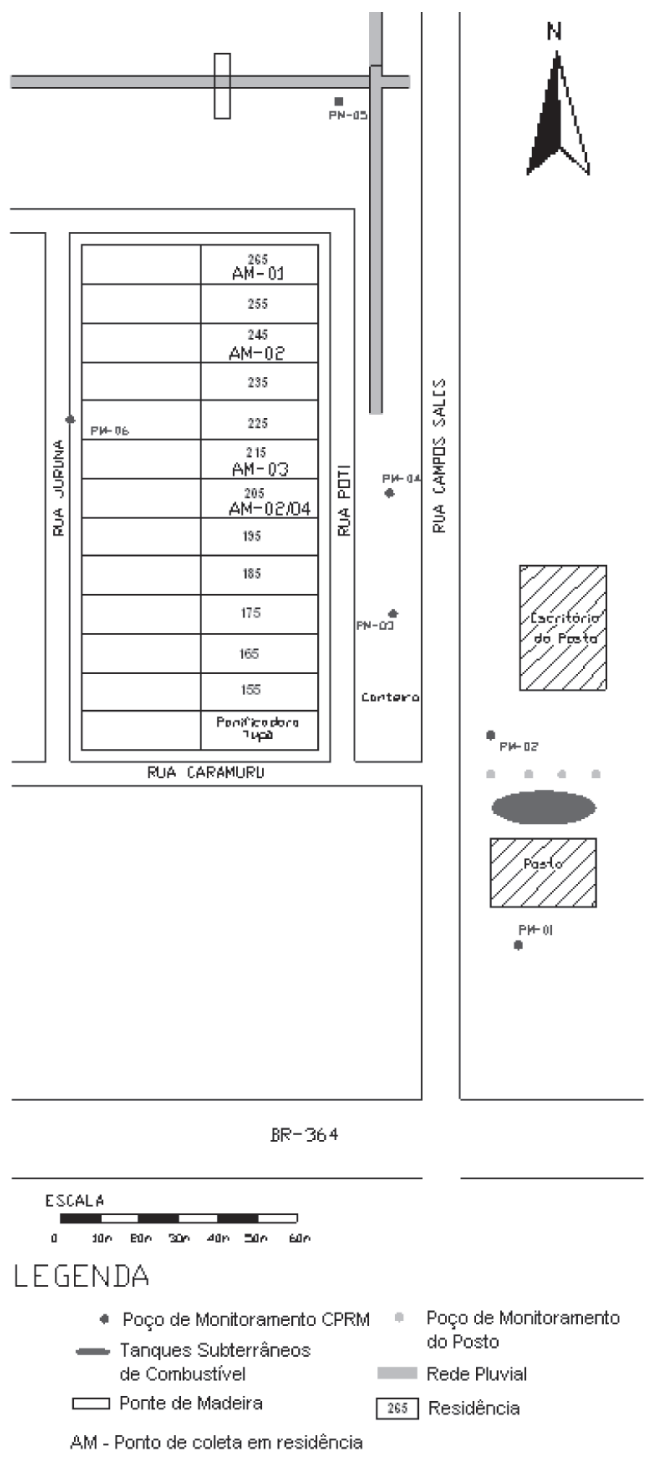

Figura 2. Croqui de localização da Vila Tupi e de todos os pontos amostrados

A amostragem foi realizada em três etapas. Na primeira etapa, no período de 7 a 9/7/2003, foram coletadas amostras de água subterrânea provenientes de poços de 3 residências da Vila Tupi (identificadas como AM-01, AM-02 e AM-03), que após serem acondicionadas em embalagem térmica foram encaminhadas para análise em laboratório no Rio de Janeiro, sendo submetidas aos exames de TPH e BTEX no Laboratório Innolab do Brasil, pertencente ao grupo Innolab $\mathrm{GmbH}$.
A segunda etapa foi realizada no dia 14 de abril de 2004, sendo coletadas amostras de água dos 6 poços de monitoramento (PM-01 a PM-06) instalados pela equipe do Serviço Geológico do Brasil CPRM e amostra de água da casa de um morador da Vila Tupi (AM-01), com o auxílio de um amostrador de água, confeccionado em PVC tendo uma válvula de retenção. As amostras foram acondicionadas em frascos de vidro de cor âmbar, boca larga, com capacidade para $1 \mathrm{~L}$. Vale ressaltar que, a coleta do poço AM-01 também fora realizada anteriormente, em julho de 2003.

Em julho de 2004, um ano após a primeira amostragem, foram coletadas novas amostras dos 6 piezômetros e da residência amostrados em abril e de mais um poço com aproximadamente 10,0 $\mathrm{m}$ de profundidade de uma residência da Vila Tupi (AM-02/04). Neste período, não se coletou amostras do Poço de Monitoramento 01, devido o mesmo ter apresentado percolação de cimento quando do processo de cimentação do poço. A Figura 2 mostra croqui de localização da Vila Tupi e de todos os pontos amostrados, verificando-se ainda a posição dos TSACs (Tanques Subterrâneos de Armazenamento de Combustíveis) do Posto.

\section{RESULTADOS E DISCUSSÃO}

\section{Análise instrumental - TPH e BTEX}

Os resultados das amostras coletadas em julho de 2003 constam na Tabela 1 e foram extraídos do boletim de análise química do Innolab.

Tabela 1. Resultado das concentrações de TPH e BTEX, em mg L-1

\begin{tabular}{lccc}
\hline Parâmetros & AM-01 & AM-02 & AM-03 \\
\hline *Benzeno & 34 & $<$ LD & $<$ LD \\
*Tolueno & 26 & 12 & 10 \\
*Etilbenzeno & 6 & 1 & 1 \\
*m-p-Xilenos & 26 & 30 & 1 \\
*O-Xileno & 21 & 27 & 1 \\
Total BTEX & 113 & 70 & 13 \\
**TPH & 0,1 & 0,1 & nd
\end{tabular}

*LD = Limite de Detecção: $1 \mathrm{mg} \mathrm{L}^{-1}$; **LD: $0,1 \mathrm{mg} \mathrm{L}^{-1}$

Conforme o próprio método utilizado na determinação do índice de hidrocarbonetos, é feita uma extração e posterior concentração, havendo perdas principalmente dos componentes voláteis, como os BTEX's. Mesmo assim, foi detectada a presença de hidrocarbonetos totais de petróleo nas amostras AM-01 e AM-02. A não detecção de TPH na amostra AM-03 não necessariamente indica a ausência de derivados de petróleo, como observado nos resultados das análises de BTEX.

$\mathrm{Na}$ amostra AM-01 detectaram-se todos os componentes pesquisados (benzeno, tolueno, etilbenzeno e xilenos) na quantidade total de $113 \mu \mathrm{g} \mathrm{L}^{-1}$. A concentração de benzeno - $34 \mu \mathrm{g} \mathrm{L}{ }^{-1}$ na amostra AM-01 (amostragem de julho de 2003) - ultrapassa os valores permitidos para consumo humano pela Portaria MS 518/04 do Ministério da $S_{a u ́ d e}{ }^{28}$, que substituiu a Portaria MS 1469/2000, que fixa a quantidade de benzeno em $5 \mu \mathrm{g} \mathrm{L}^{-1}$ e que é utilizado pela $\mathrm{CETESB}^{29}$, por ex., como valor para intervenção, sendo necessárias, para estes valores, medidas de remediação imediatas. Também ultrapassa o valor máximo permitido nos corpos d'água conforme a Resolução nº 20/86 do $\mathrm{CONAMA}^{30}$, que fixa em $10 \mu \mathrm{g} \mathrm{L}^{-1}$.

É bom salientar que o Estado de Rondônia no Decreto n ${ }^{\circ} 7903$, de 01 de julho de 1997, que regulamenta a Lei Estadual $n^{\circ} 547$ de 30 de dezembro de 1993 e que dispõe sobre proteção, recuperação, 
controle, fiscalização e melhoria da qualidade do meio ambiente, fixou como limite os mesmos valores da Resolução $n^{\circ}$ 20/86 do CONAMA, não específicos para águas subterrâneas ${ }^{31}$. Os valores detectados indicam um grave risco no consumo dessa água pela população que, por exposição crônica, pode desenvolver doenças do sistema nervoso central ou leucemia ${ }^{18}$.

A detecção de BTEX nas amostras AM-01, AM-02 e AM-03 mostra que a pluma poluidora avançou em direção à Vila, tendo em vista a distância das residências ao posto de gasolina. $\mathrm{O}$ alto índice pluviométrico na cidade de Porto Velho e a exploração dos aquiíferos dos quais são retiradas as águas contribuem decisivamente para este avanço, na medida em que aumenta a velocidade do fluxo subterrâneo em direção às áreas onde está havendo a retirada de água, caracterizado pelo bombeamento, que pode alterar as configurações do fluxo de água subterrânea e, conseqüentemente, alterar o movimento de uma pluma contaminante ${ }^{20}$.

\section{Óleos, graxas e hidrocarbonetos - método de partição gravimétrica}

Em abril de 2004 foram verificados parâmetros físicos, como temperatura da água, $\mathrm{pH}$ e condutividade elétrica da água; temperatura do ar e profundidade do nível da água a partir da superfície, sendo observado odor característico de combustível derivado de petróleo em algumas amostras, fortalecendo as evidências da presença de hidrocarbonetos.

$\mathrm{Na}$ amostragem efetuada em julho de 2004 ainda se observou o odor característico de combustível nos poços de monitoramento 02 e 03 e nos poços das residências amostradas. Foi observada também variação considerável do nível das águas (NA), em relação à superfície, de uma amostragem para outra. Foram efetuadas análises visando determinar a concentração de óleos, graxas e hidrocarbonetos (Tabela 2).

Observando-se, na Tabela 2, os valores detectados e os mapas de isoconcentrações de óleos, graxas e de hidrocarbonetos do PM03 do mês de julho de 2004, verifica-se que essas são maiores que as concentrações do PM-02. Em abril de 2004 ocorreu o inverso.

Os mesmos mapas mostram, nos períodos amostrados, a dispersão da pluma de contaminantes a partir do posto e a persistência dos hidrocarbonetos, sendo observada uma diminuição nos teores dos parâmetros pesquisados caracterizando uma atenuação natural. Verifica-se ainda um espalhamento da pluma e sua migração acompanhando o fluxo subterrâneo (Figuras 3 a 6), devendo ser tomadas medidas urgentes na área, como a interdição preventiva dos poços de abastecimento das residências da Vila e realizados estudos mais detalhados visando medidas de remediação pois os moradores, a persistirem no consumo destas águas, continuarão a sentir os problemas da contaminação caracterizada pela presença indesejável de hidrocarbonetos, haja vista a sazonalidade do aqüífero, que se movimenta verticalmente acompanhando os movimentos de cheia e seca, observada na variação do nível da água (N.A.) constante na Tabela 2.

Salienta-se que no período de janeiro a maio e setembro a dezembro ocorre excedente hídrico significativo em Porto Velho, acima de $900 \mathrm{~mm} / \mathrm{ano}$, que possibilita a recarga do aqǘf́fero ${ }^{32}$. Nos meses de junho a agosto as precipitações pluviométricas diminuem significativamente, ocorrendo uma deficiência hídrica, ou seja, a precipitação é menor que a umidade requerida pela evapotranspiração ${ }^{32}$.

\section{CONCLUSÕES}

Verificou-se a presença de hidrocarbonetos derivados de petróleo nas amostras de água analisadas e coletadas de poços de monitoramento
Tabela 2. Valores em $\mathrm{mg} \mathrm{L}^{-1}$ de óleos, graxas e hidrocarbonetos nas amostras de água e nível das águas (N.A.) em m, nos meses de abril e julho de 2004

\begin{tabular}{lcccccc}
\hline Amostras & \multicolumn{2}{c}{$\begin{array}{c}\text { Óleos e Graxas } \\
\left(\mathrm{mg} \mathrm{L}^{-1}\right)\end{array}$} & \multicolumn{2}{c}{$\begin{array}{c}\text { Hidrocarbonetos } \\
\left(\mathrm{mg} \mathrm{L}^{-1}\right)\end{array}$} & \multicolumn{2}{c}{ Nível da } \\
& Abr & Jul & Abr & Jul & Abr & Jul \\
\hline PM-01 & 193 & - & 95 & - & 2,90 & - \\
PM-02 & 104 & 47 & 46 & 28 & 4,85 & 5,58 \\
PM-03 & 88 & 67 & 38 & 65 & 5,33 & 5,97 \\
PM-04 & 63 & 34 & 14 & 23 & 4,32 & 5,21 \\
PM-05 & 65 & 19 & 41 & 8 & 2,80 & 3,61 \\
PM-06 & 80 & 26 & 32 & 9 & 6,20 & 6,99 \\
AM-01 & 53 & 33 & 23 & 14 & 3,60 & 5,00 \\
AM-02/04 & - & 31 & - & 23 & - & 7,40 \\
\hline
\end{tabular}

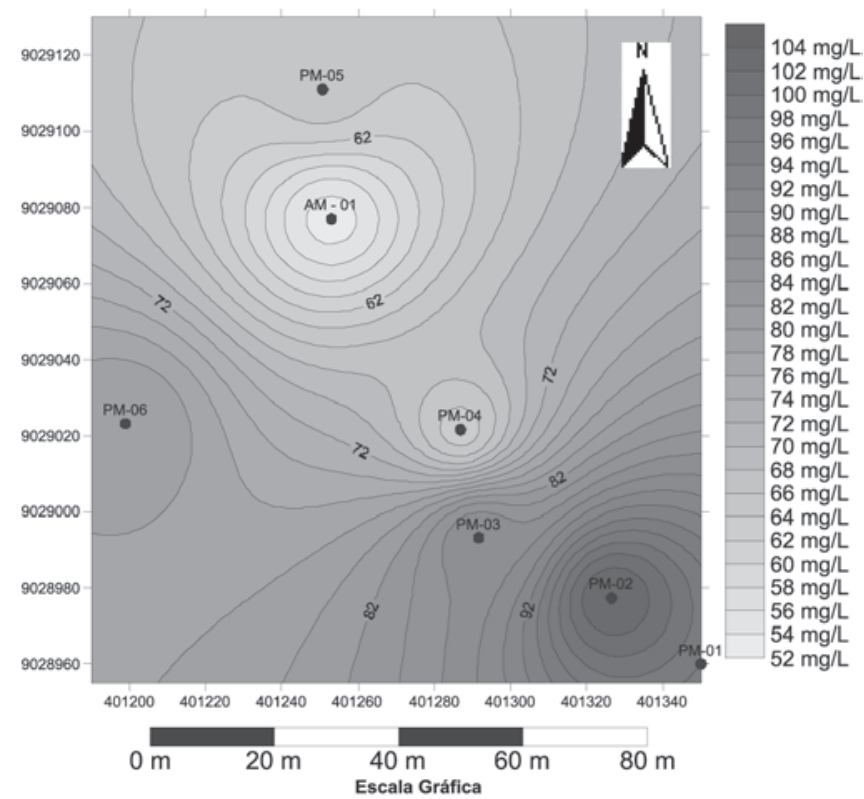

Figura 3. Mapa (com coordenadas em UTM) das concentrações de óleos e graxas - abril de 2004

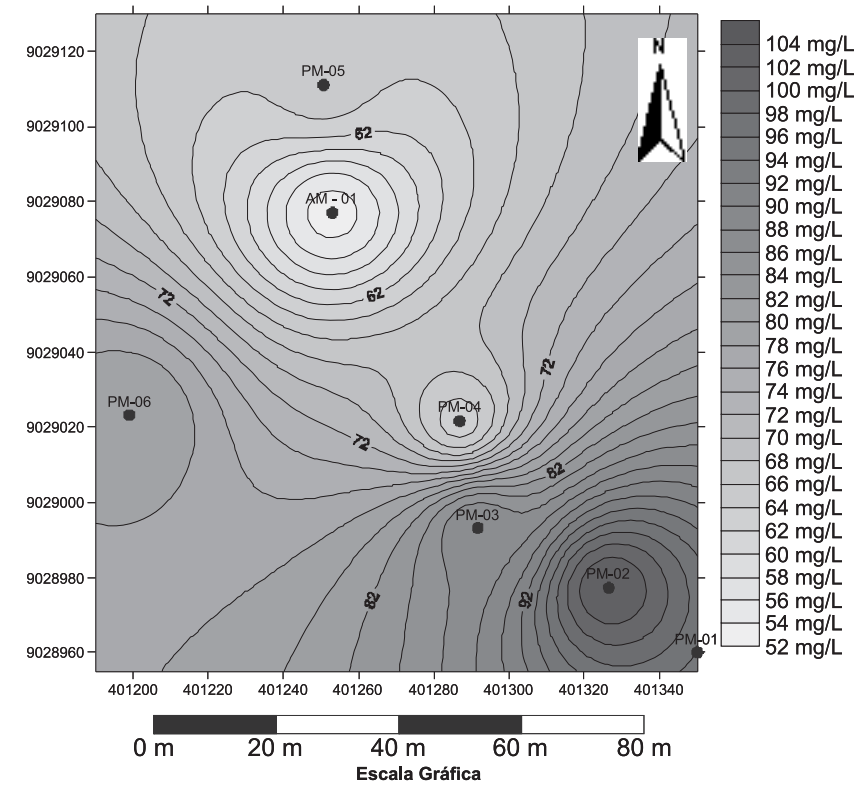

Figura 4. Mapa (com coordenadas em UTM) das concentrações de hidrocarbonetos - abril de 2004 


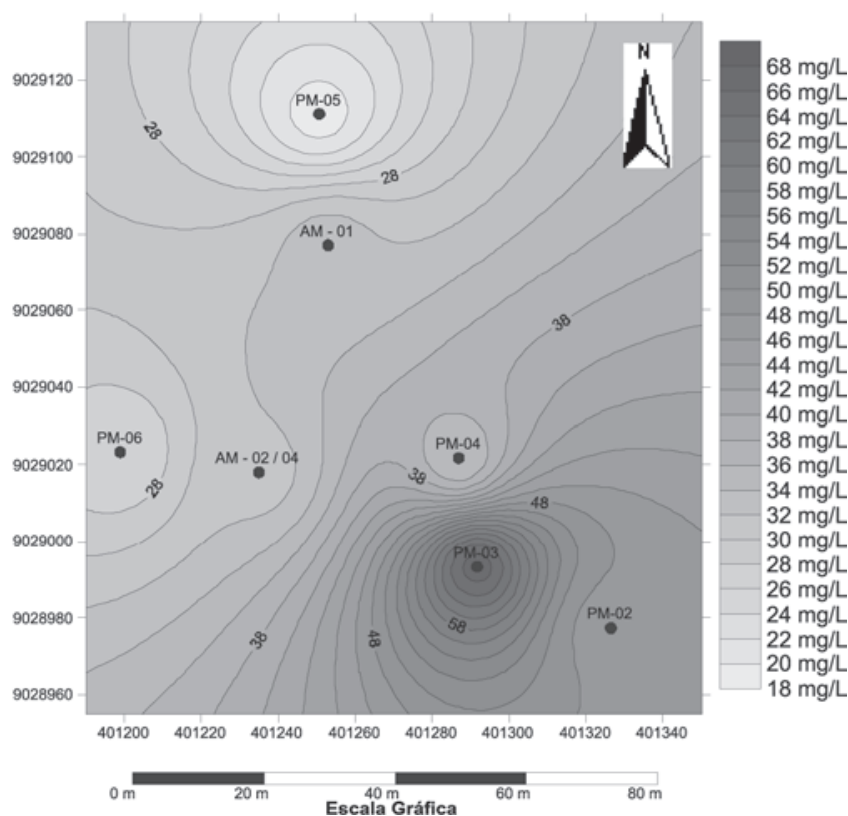

Figura 5. Mapa (com coordenadas em UTM) das concentrações de óleos e graxas - julho de 2004

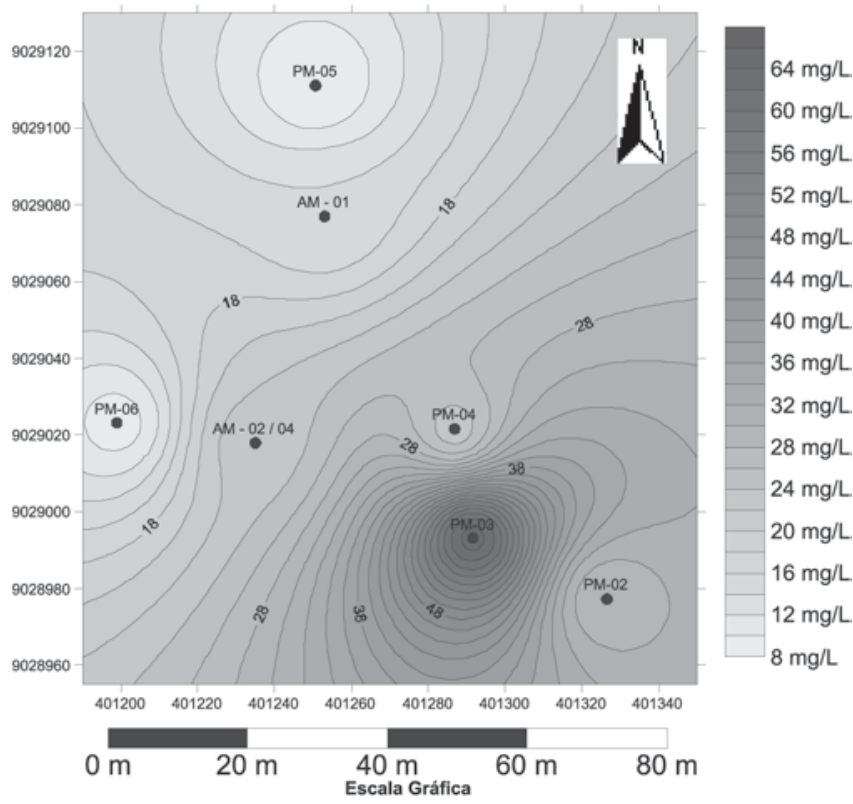

Figura 6. Mapa (com coordenadas em UTM) das concentrações de hidrocarbonetos - julho de 2004

e de poços utilizados como fontes de abastecimento na Vila Tupi, em Porto Velho, caracterizando ação antropogênica na área estudada.

As metodologias empregadas serviram para o diagnóstico de hidrocarbonetos, podendo inclusive ser utilizadas no monitoramento de aquíferos por postos revendedores de combustíveis, atentandose, porém, para o uso em problemas de derramamento de combustíveis ou quando de vazamento muito antigo, quando o solo já estará saturado. A análise para hidrocarbonetos é mais específica e é feita a partir dos resquícios dos resíduos de óleos e graxas analisados. Deve-se levar em conta ainda que estas análises não possibilitam a avaliação do grau de periculosidade individual.

O uso da cromatografia gasosa é conveniente, principalmente pelo baixo custo do traçado do perfil cromatográfico. Foi caracteri- zado o deslocamento da pluma de contaminação acompanhando o fluxo subterrâneo na direção da Vila Tupi, tendo em vista as características físico-químicas dos hidrocarbonetos detectados e o bombeamento dos aqüíferos, aumentando a extensão da pluma. A permeabilidade do solo na área e o alto índice pluviométrico na cidade de Porto Velho também contribuem para este deslocamento, além da influência do etanol.

Os dados obtidos de amostras de água coletadas dos poços de monitoramento distribuídos na área estudada e de poços de abastecimento de residências da Vila Tupi, que apresentaram teores de óleos e graxas de $193 \mathrm{mg} \mathrm{L}^{-1}$ (máximo) em abril de 2004 no PM-01 e $19 \mathrm{mg} \mathrm{L}^{-1}$ (mínimo) em julho de 2004 no PM-05 e teores de hidrocarbonetos entre $95 \mathrm{mg} \mathrm{L}^{-1}$ (máximo) em abril de 2004 no PM01 e $14 \mathrm{mg} \mathrm{L}^{-1}$ (mínimo) em julho de 2004 na amostra AM-01, permitem concluir que os hidrocarbonetos detectados nas águas subterrâneas analisadas são oriundos do posto revendedor de combustíveis localizado próximo à Vila, única fonte potencial de contaminação por estes compostos nas proximidades.

$\mathrm{O}$ teor de benzeno $\left(34 \mu \mathrm{g} \mathrm{L}^{-1}\right)$ encontrado na amostra de água AM-01, do poço de uma residência da Vila Tupi, ultrapassa o valor fixado de $5 \mu \mathrm{g} \mathrm{L}^{-1}$ pela Portaria MS 518/04 para potabilidade, valor usado pela CETESB para intervenção em uma área contaminada.

O plano de estudos proposto neste trabalho pode ser aplicado para diversas áreas que possuam fontes potenciais de contaminação por hidrocarbonetos, como postos revendedores de combustíveis, distribuidoras de combustíveis, lava jatos e oficinas mecânicas. É importante, a partir desta metodologia, expandir os estudos visando estabelecer valores orientadores para a proteção da qualidade de solos e águas subterrâneas da cidade de Porto Velho e do Estado de Rondônia, visando estratégias para minimizar os danos causados ao meio ambiente.

\section{REFERÊNCIAS}

1. http://www.cetesb.sp.gov.br/emergencia/acidentes/postos/introducao.asp, acessada em Maio 2004.

2. http:// www.anp.gov.br, acessada em Agosto 2004

3. http//www.ibge.gov.br, acessada em Agosto 2004.

4. Baird, C.; Química Ambiental, 2ª ed., Bookman: Porto Alegre, 2002.

5. http://www.cee.vt.edu.programareas/environmental/teach/gwprimer/btex/ btex.html, acessada em Agosto 2003.

6. Tiburtius, E. R. L.; Peralta-Zamora, P.; Leal, E. S.; Quim. Nova 2004, 27, 441.

7. Azevêdo, F. A.; Chasin, A. A. M.; As bases toxicológicas da ecotoxicologia, RiMa Intertoxi: São Paulo, 2003.

8. Finotti, A. R.; Caicedo, N. O. L.; Rodriguez, M. T. R.; Revista Brasileira de Recursos Hídricos 2001, 6, 2.

9. Silva, R. L. B.; Barra, C. M.; Monteiro, T. C. N.; Brilhante, O. M.; Caderno de Saúde Pública 2002, 18, 1599.

10. Souza, E. L.; Dos Anjos, G. C. Em Contaminação das águas subterrâneas: uma visão parcial da situação de Belém e dos problemas decorrentes; Uhly S.; de Souza, E. L., orgs.; Casa de Estudos Germânicos - Fundação Heinrich Böll: Belém, 2004.

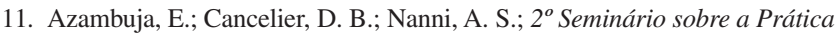
de Engenharia Geotécnica da Região Sul, Porto Alegre, Brasil, 2000.

12. Duarte, K. S.; Tese de Doutorado, Universidade de Brasília, Brasil, 2003.

13. Cordazzo, J.; Dissertação de Mestrado, Universidade Federal de Santa Catarina, Brasil, 2000.

14. Foster, S. D.; Gomes, D. C.; Monitoreo de la calidad de las águas subterrâneas: una evaluación de métodos y costos, CEPIS/OPS/OMS, 1989.

15. Ministério da Agricultura, Pecuária e Abastecimento - MAPA. Portarias n ${ }^{\text {os }}$ 554 , de 27 de maio de 2003; 51, de 22 de fevereiro de 2006 e 278, de 10 de novembro de 2006.

16. Corseuil, H. X.; Fernandes, M.; Revista Engenharia Sanitária e Ambiental 1999, 4, 71.

17. Corseuil, H.; Moreno, F. N.; Water Res. 2001, 35, 3013

18. Corseuil, H. X.; Marins, M.; Boletim Técnico Petrobrás 1998, 41, 133.

19. Firta, I. N.; Dissertação de Mestrado, Universidade Federal de Santa Catarina, Brasil, 2001

20. Clearly, R. W.; Miller, D. W.; Aspectos fundamentais e monitoramento de poluição de água subterrânea, CEPIS/OPS/OMS, 1984.

21. Melo Jr., H. R.; Costi, A. C.; Relatório Final, CPRM; Porto Velho, 2004. 
22. Agudo, E. A.; Guia de coleta e preservação de amostras de água, CETESB: São Paulo, 1987.

23. http://www.epa.gov/epaoswer/hazwaste/test/pdfs/8260b.pdf, acessada em Dezembro 2005.

24. Macêdo, J. A. B.; Águas \& Águas - Métodos Laboratoriais de Análises Físico-Químicas e Microbiológicas, Macedo: Juiz de Fora, 2001.

25. APHA-AWWA-WPCF; Métodos Normalizados para el análisis de águas potables y residuales; Ediciones Diaz de Santos, S.A.: Madri, 1992.

26. Golden Software, Inc; SURFER 8.0; Colorado, USA, 2002.

27. Landim, P. M. B.; Análise estatística de dados geológicos, Fundação Editora da UNESP: São Paulo, 1998, p. 226.
28. http://www.anvisa.gov.br, acessada em Julho 2004.

29. Companhia de Tecnologia de Saneamento Ambiental (CETESB); Relatório de estabelecimento de valores orientadores para solos e águas subterrâneas no estado de São Paulo, São Paulo, 2001.

30. Conselho Nacional do Meio Ambiente (CONAMA); Resoluções do CONAMA 1984-1991, 4ª . ed., IBAMA: Brasília, 1992

31. http//:www.rondonia.ro.gov.br, acessada em Novembro 2003.

32. CPRM - Serviço Geológico de Brasil; Mapa hidrogeológico do Estado de Rondônia, CPRM: Porto Velho, 1998. 